\title{
REASSESSMENT OF SELECTED HEALTHCARE ASSOCIATED RISK FACTORS FOR HBV AND HCV INFECTIONS AMONG VOLUNTEER BLOOD DONORS, KARACHI, PAKISTAN
}

\author{
Muhammad Younus ${ }^{1}$, Azfar-e-Alam Siddiqi', Saeed Akhtar ${ }^{2}$ \\ ${ }^{1}$ Dept. of Epidemiology, College of Human Medicine, Michigan State University, USA \\ ${ }^{2}$ Dept. of Community Medicine and Behavioral Sciences, Kuwait University, Kuwait and Dept. of Community Health Sciences, The Aga Khan \\ University, Karachi, Pakistan
}

\section{SUMMARY}

Epidemiologic studies conducted in the 1990s identified several independent healthcare associated risk factors for HBV and HCV infections in Pakistan. In 2002, we re-examined healthcare associated HBV and/or HCV infection risk factors in volunteer blood donors.

In this case-control study, we collected data using a structured questionnaire on socioeconomic attributes, putative healthcare related risk factors, and other known factors for HBV and HCV infections in Karachi, Pakistan.

The multivariable logistic-regression model (166 cases, 394 controls) after adjusting for socio-demographic attributes and other known HBV and HCV risk factors revealed that more cases than controls had multiple lifetime hospitalization, adjusted odds ratio (AOR) $=2.48 ; 95 \%$ confidence interval $(\mathrm{Cl}) 1.04,5.94$, and had received dental treatment from an unqualified provider ( $\mathrm{AOR}=5.90, \mathrm{Cl}, 1.66,21.02)$. More cases than controls had received a large number of therapeutic injections during the last 5 years (1-5 injections vs. $0, A O R=2.64,95 \% \mathrm{Cl} 1.06,6.60 ; 6-19$ injections vs. $0, A O R=4.09,95 \% \mathrm{Cl} 1.59,10.51 ; \geq 20$ injections vs. $0, A O R=4.34,95 \% \mathrm{Cl} 1.70,11.07)$, and had their last injection given using a re-usable glass syringe (AOR=3.41 Cl 1.13,10.29).

Our data suggest that risk factors for HBV and HCV infections identified in the last decade have remained unchanged in healthcare facilities in Karachi. Additional multi-disciplinary efforts are needed to control healthcare associated HBV and HCV transmission in Pakistan.

Key words: healthcare, hepatitis B virus, hepatitis C virus, risk factors, blood donors, developing countries, Pakistan

Address for correspondence: Azfar-e-Alam Siddiqi, Biomedical Research \& Informatics Center, Department of Epidemiology, Michigan State University, 100 Conrad Hall, East Lansing, Ml 48824, USA. E-mail: siddiqi@msu.edu, azfar.siddiqi@ht.msu.edu

\section{INTRODUCTION}

Inadequate infection control practices in healthcare settings have been shown by epidemiologic investigations, to contribute significantly to the global burden of hepatitis B virus (HBV) and hepatitis $\mathrm{C}$ virus (HCV) infections. This is particularly true in developing countries around the world such as Pakistan (1-3).

Historically hepatitis has been a menace across the world without regards to geographical boundaries, socio-cultural and economic divide. Recognizing this problem, the universal guidelines for infection control were developed in late 1980s (4), and their implementation in the developed nations has led to the application of rigorous infection control practices in healthcare settings. In conjunction with quality assurance systems, higher occupational safety standards, and greater recognition of and respect for patients' rights, the universal precautions have resulted in a dramatic improvement in infection control $(1,5)$. The situation in developing countries such as Pakistan, however, remained unchanged, as standardized infection control did not become widely implemented and/or practiced (6).

Observational studies conducted in the past decade identified parenteral exposures in healthcare settings, including the use of unsterile medical or dental equipment, and intramuscular (IM) and intravenous (IV) therapeutic injections, as major contributors to HBV and HCV infection cases in Pakistan (7-9). In Pakistan, it wasn't until mid 1990s that the efforts were initiated by public health legislators, healthcare providers, and communities towards implementation of several infection control and prevention measures to reduce healthcare associated infections including $\mathrm{HBV}$ and HCV. An integral part of these efforts were advocacy for campaigns for HBV vaccination. (10).

Several years have passed since initiation of these efforts that, common sense dictates, must have had some impact on practices that were previously found to contribute to spread of $\mathrm{HBV}$ and/or $\mathrm{HCV}$ infections in Pakistan. However, no or minimal efforts have been made to gauge the impact of these efforts, or to quantitatively assess the current magnitude of healthcare associated risk factors for $\mathrm{HBV}$ and $\mathrm{HCV}$ infections.

The relative importance of the modes of transmission of an infectious disease can change over time, particularly when rejuvenated efforts are made to control its spread. The periodic evaluation of the common modes of transmission of a disease is therefore important, as it not only helps public health officials in developing specific prevention and control strategies for a given transmissible infection, but also helps to evaluate the impact of such control strategies. 
Quantitative data regarding the transmission of $\mathrm{HBV}$ and $\mathrm{HCV}$ in healthcare settings are needed in order to design an evidence-based optimal infection control strategy in healthcare settings in Pakistan. This research was a secondary analysis of a large case-control study and carried out as a post-implementation assessment of infection control practices by reevaluating the healthcare associated risk factors for $\mathrm{HBV}$ and $\mathrm{HCV}$ infections reported in earlier investigations in Pakistan. This paper is an effort to help fill this gap in understanding of the current status of risk factors of $\mathrm{HBV}$ and/or HCV and to indirectly assess the impact of infection control practices and campaigns on previously identified risk factors, for HBV and/or HCV infections.

\section{MATERIALS AND METHODS}

\section{Study Setting, Population and Subject Recruitment}

The methodological details of the primary study have been described elsewhere (11) and are briefly outlined here. This casecontrol study was carried out in 2002 in Karachi, the largest city of Pakistan with a population of over 14 million. The study was conducted at two large blood banks in Karachi that collect blood donations from only non-remunerated volunteers. Both blood banks follow similar donor criteria and exclude potential donors during the screening process who admit known risk factors of transfusion transmissible infections or any medical/non-medical condition associated with high risk, such as use of narcotic drugs, jaundice in the past 5 years, and recent hospitalization. Male blood donors aged 18-64 years who donated blood were contacted after obtaining addresses and phone numbers from the blood banks' records. Both blood banks used commercially available enzyme-linked immunosorbent assay (ELISA-III) kits to test for seropositivity against $\mathrm{HBV}$ ( $\mathrm{HBsAg}$ ) and $\mathrm{HCV}$ (HCVantibody) in donated blood.

\section{Cases and Controls}

Case subjects were blood donors found seropositive for $\mathrm{HCV}$ antibody and/or HBsAg in the blood banks' records between October 2001 and March 2002. The identified donors were contacted and explained the purpose of the study and requested to donate a fresh blood sample. The fresh blood samples were re-tested and only blood donors who were positive for HCV and/or HBV on the second sample were considered cases. The control group included HCV and HBV seronegative blood donors from the same blood banks. We excluded cases and controls testing reactive for other transmissible diseases such as human immunodeficiency virus (HIV) and malaria.

\section{Questionnaire Development, Subject Recruitment and Interview Procedure}

An in-person interview with each study subject was conducted using a structured questionnaire on demographic and socioeconomic characteristics (e.g., age, ethnicity, education, income), various potential exposures to blood or blood products (e.g., history of hospitalization, therapeutic injections/intravenous infusions received), sexual activity (e.g., number of sexual partners), and household exposure to hepatitis (e.g., history of hepatitis in a family). We included questions that could provide quantitative data regarding HBV and HCV risk factors: lifetime number of hospitalizations, number of dental treatment received during the last 5 years, and number of intramuscular (IM) and intravenous (IV) injections received during the last 5 years. The questionnaires were administered through trained interviewers.

\section{Ethics}

Prior to interview, each potential study subject provided verbal informed consent. The Institutional Review Committee (IRC) for human research at the Aga Khan University approved the protocol.

\section{Statistical analysis}

A database was developed in Epi Info (CDC version 6.0, 1996) for data entry, cleaning and management, while all analyses were performed using $\mathrm{SAS}^{1}$ software version 9 . Frequencies of all the categorical variables were computed for cases and controls. Crude odds ratios (ORs) and 95\% confidence intervals (CIs) were calculated using logistic regression, relating each factor with $\mathrm{HCV}$ and/or HBsAg positive status. To examine the independent con-

Table 1. Socio-demographic characteristics of cases and controls enrolled to assess healthcare care associated HBV and/or HCV risk factors in Karachi, Pakistan

\begin{tabular}{|c|c|c|}
\hline & $\begin{array}{c}\text { Case } \\
(\mathbf{n}=166) \\
\mathbf{n}(\%)\end{array}$ & $\begin{array}{c}\text { Control } \\
\mathbf{( n = 3 9 4 )} \\
\mathbf{n}(\%)\end{array}$ \\
\hline Age (completed years) & $57(34.3)$ & $212(53.8)$ \\
\hline $18-25$ & $93(56.0)$ & $159(40.4)$ \\
\hline $26-40$ & $16(9.7)$ & $23(5.8)$ \\
\hline$>40$ & & \\
\hline Formal schooling (completed years) & $30(18.1)$ & $98(24.9)$ \\
\hline 0 & $59(35.5)$ & $101(25.63)$ \\
\hline $1-10$ & $28(17.5)$ & $58(14.72)$ \\
\hline $11-12$ & $48(28.9)$ & $137(34.77)$ \\
\hline$>12$ & & \\
\hline Profession/occupation & $19(11.5)$ & $70(17.77)$ \\
\hline Student & $95(57.2)$ & $194(49.24)$ \\
\hline Self employed/Office worker & $52(31.3)$ & $130(32.99)$ \\
\hline Manual worker/Un-employed & & \\
\hline Household income (PKR*/month) & $19(11.5)$ & $54(13.71)$ \\
\hline$>15,000$ & $60(36.1)$ & $97(24.62)$ \\
\hline $8,001-15,000$ & $25(15.1)$ & $62(15.74)$ \\
\hline $5,001-8,000$ & $42(25.3)$ & $102(25.89)$ \\
\hline$\leq 5,000$ & $20(12.0)$ & $79(20.05)$ \\
\hline Refused to answer & & \\
\hline
\end{tabular}

*PKR: Pakistani rupees (1 $\$=\sim 60 \mathrm{PKR}$, in 2002)

\footnotetext{
${ }^{1}$ The analysis for this paper was generated using SAS/STAT software, Version 9. SAS and all other SAS Institute Inc. product or service names are registered trademarks or trademarks of SAS Institute Inc., Cary, NC, US
} 
Table 2. Un-adjusted and adjusted odds ratios (ORs) with 95\% confidence intervals (Cls) for healthcare associated HBV and/or HCV infections assessed in a case-control study in Karachi, Pakistan

\begin{tabular}{|c|c|c|c|c|}
\hline & $\begin{array}{c}\text { Cases } \\
n=166 \\
n(\%)\end{array}$ & $\begin{array}{c}\text { Controls } \\
\mathrm{n}=394 \\
\mathrm{n}(\%)\end{array}$ & $\begin{array}{l}\text { Un-adjusted OR } \\
(95 \% \mathrm{Cl})\end{array}$ & $\begin{array}{c}\text { Adjusted OR } \\
\quad(95 \% \mathrm{Cl})\end{array}$ \\
\hline \multicolumn{5}{|l|}{ History of hospital admission } \\
\hline 0 & $106(63.9)$ & $293(74.4)$ & reference & reference \\
\hline 1 & $43(25.9)$ & $83(21.1)$ & $1.43(0.93,2.20)$ & $1.48(0.87,2.52)$ \\
\hline$>1$ & $17(10.2)$ & $18(4.6)$ & $2.61(1.29,5.25)$ & $2.48(1.04,5.94)^{*}$ \\
\hline \multicolumn{5}{|l|}{ History of dental treatment } \\
\hline Never had dental treatment & $97(58.4)$ & $272(69)$ & reference & reference \\
\hline Treated by dentist & $51(30.7)$ & $118(29.9)$ & $1.21(0.81,1.81)$ & $0.99(0.61,1.63)$ \\
\hline Treated by others & $18(10.8)$ & $4(1.0)$ & $12.61(4.16,38.20)$ & $5.90(1.66,21.02)^{\star}$ \\
\hline \multicolumn{5}{|l|}{ IM injections received in last 5 years } \\
\hline 0 & $18(10.8)$ & $127(32.8)$ & reference & reference \\
\hline $1-5$ & $45(27.1)$ & $128(33.1)$ & $2.48(1.36,4.51)$ & $2.64(1.06,6.60)^{*}$ \\
\hline $6-19$ & $47(28.3)$ & $76(19.6)$ & $4.36(2.36,8.05)$ & $4.09(1.59,10.51)^{\star}$ \\
\hline$\geq 20$ & $56(33.7)$ & $56(14.5)$ & $6.27(3.40,11.55)$ & $4.34(1.70,11.07)^{\star}$ \\
\hline \multicolumn{5}{|c|}{ Type of syringe used for the last IM injection } \\
\hline No injection received & $9(5.4)$ & $88(22.3)$ & reference & reference \\
\hline Disposable plastic syringe & $100(60.2)$ & $256(65)$ & $3.81(1.85,7.87)$ & $1.01(0.32,3.16)$ \\
\hline Reusable glass syringe & $57(34.3)$ & $50(12.7)$ & $11.14(5.08,24.41)$ & $3.41(1.13,10.29)^{*}$ \\
\hline \multicolumn{5}{|c|}{ Handle blood/blood products in any form } \\
\hline No & $159(95.8)$ & $386(98)$ & reference & reference \\
\hline Yes & $7(4.2)$ & $8(2.0)$ & $2.12(0.75,5.95)$ & $2.51(0.71,8.88)$ \\
\hline
\end{tabular}

*Significant at 0.05

$\mathrm{Cl}$ : Confidence interval

Multivariable model is adjusted for age, race, household income, family history of HBV and/or HCV, sexual intercourse with a person who is high-risk for HBV and/or $\mathrm{HCV}$ (e.g., commercial sex worker, injecting drug user), and injury received during facial shaving from barber - a recognized risk factor for HBV and/or HCV in Pakistan)

tribution of each healthcare associated risk factor for HBV and/or HCV infections, a multivariable logistic regression (MLR) model was developed, and adjusted ORs (AORs) with their respective 95\% CIs were computed.

\section{RESULTS}

A total of 166 cases and 394 controls were enrolled during the study period. The socioeconomic and demographic characteristics of cases and controls are presented in Table 1. When adjusted for socio-demographic characteristics and known risk factors for $\mathrm{HBV}$ and/or HCV, the final MLR model revealed that more cases than controls had at least 1 lifetime hospitalization, $\mathrm{AOR}=2.48$; 95\% CI, 1.04, 5.94, and had received dental treatment from an unqualified provider, $\mathrm{AOR}=5.90, \mathrm{CI}, 1.66,21.02$. More cases than controls also had received a large number of therapeutic injections during the last 5 years $(1-5$ vs. $0, A O R=2.64,95 \% \mathrm{CI}$, $1.06,6.60 ; 6-19$ vs. $0, \mathrm{AOR}=4.09,95 \% \mathrm{CI}, 1.59,10.51 ; \geq 20$ vs. $0, \mathrm{AOR}=4.34,95 \% \mathrm{CI}, 1.70,11.07)$, and had their last injection given using a reusable glass syringe $(\mathrm{AOR}=3.41 \mathrm{CI}, 1.13,10.29)$ (Table 2).

\section{DISCUSSION}

This study reassessed selected healthcare associated risk factors for HBV and HCV infections identified during the past decade in Pakistan. Our analysis identified several factors that were associated with HBV and/or HCV infection. Case patients were significantly more likely to report multiple life time hospitalization as compared to controls. This finding is consistent with reports in literature that found such an association in developing countries $(12,13)$. This finding even after a decade of introduction of the standardized infection control practices indicate towards an improper implementation of these measures.

Therapeutic injections received at healthcare facilities have been reported as the major risk factor for both HBV and HCV infection in the developing world. Similar to earlier reports $(6,7$, $13,14)$, our data showed a positive association between a large number of IM injection received in the past five years and HBV and/or HCV seropositive status. A dose-response gradient between the number of IM injection received and HBV and/or HCV serostatus was also observed, i.e., the number of IM injections received in the past five years increased, as the odds of being HBV and/or HCV seropositive increased. 
Luby et al. (7) were among the first in Pakistan to provide empirical evidence of the association between frequent therapeutic IM injections and the spread of HBV and HCV infections from an epidemiological study in Punjab, Pakistan. This situation has remained unchanged as evident from findings of subsequent studies $(14,15)$. Replication of these findings in our study is another indicator that no major changes have occurred over time. Even more recently it has been estimated that an average Pakistani receives an estimated 13.6 injections per year (14), and that majority of these injections are administered under unsafe conditions (16), exposing the patient to several blood borne pathogens, including HBV and HCV.

Importance of injections in spreading blood transmittable diseases such as hepatitis is well documented $(17,18)$. The availability of injectable medications and equipment without a physician's prescription further compounds this problem (5).

Individuals with $\mathrm{HBV}$ and/or HCV infection were more likely to report receiving dental treatment from unqualified providers. Dental practice by unregistered and unqualified providers is not uncommon in developing countries, including Pakistan. Investigations have shown an association between unqualified dental care provider and HBV and HCV infections $(19,20)$. These providers are un-aware of infection control practices and often use unsterilized instruments. Additionally the infection control initiative in Pakistan focused exclusively on registered and legal health care providers and establishments, thus we didn't expect and were not surprised by seeing dental care by unqualified person to be a continuing risk factor of $\mathrm{HBV}$ and/or $\mathrm{HCV}$ infections.

A few limitations of our study are worth mentioning. Our findings' generalizability is limited to the male volunteer donors. However, since no sex-specific risk factors for healthcare associated $\mathrm{HBV}$ and $\mathrm{HCV}$ infections were identified, we expect our findings to be applicable across both sexes. Additionally, any public health measure in blood donors will likely have most success when it targets males, as a vast majority of blood donors in Pakistani culture are males. Since, we collected the data retrospectively using a case-control study design (21), it is not possible to completely avoid or eliminate recall bias. However, all of the factors that we explored and they were retained in the final multivariate model were health care related and clearly defined, involving simple recall. We therefore expect recall inaccuracies to be similar in both groups and not different based on case or control status of the patients. The resultant 'bias' if any would make our estimates a little conservative but valid. All risk factor data were generated by self-reports. Therefore, participants may have responded cautiously to questions about culturally sensitive high-risk behaviors, such as extra-marital sexual activities; leading to under-reporting and underestimation of some risk behaviors. However, we expect this under-reporting to be similar for both cases and controls and any resultant response bias, would be non-differential in nature. Therefore, the observed exposure disease relationship may be more conservative but still valid. For HCV evaluation, we used $\mathrm{HCV}$ antibody as a serological marker, which only indicates prior exposure to $\mathrm{HCV}$ and does not specify the duration of infections. We used HBsAg for the evaluation of HBV infection; which, in the majority of infected individuals is not detectable 4-6 weeks post infection. This guarantees accurate recruitment of HBV cases as per our case definition, but leaves open the possibility that some of our controls might have been infected with HBV in the past and may not have been true controls. This again might have lead to under-estimation of strength of association of some factors but it doesn't threat the validity of our findings.

Our method of combining HBV and HCV cases in our outcome variable and obtaining a single effect size for both infections may be considered unconventional by some. However, since our objective was to identify healthcare related risk factors for HBV and $\mathrm{HCV}$, and both infections are efficiently acquired through parenteral exposures and also share similar transmission routes in healthcare settings, we consider this combination justifiable. Although we collected data on several types of parenteral exposures associated with healthcare facilities (e.g., number of IV injections received in the last one, five, and ten years, and body injury requiring consultation with a doctor), the strong correlations $(p<0.05)$ among these variables (multicollinearity) restricted our variable selection. The final MLR model was therefore restricted to the variables that best explained our outcome of interest.

\section{Conclusion}

In conclusion, our data suggest that risk factors for HBV and $\mathrm{HCV}$ identified in the last decade have remained unchanged in healthcare facilities in Karachi. Despite recent control efforts, inadequate infection control practices in healthcare settings seem to continue to play a role in the spread of HBV and HCV in Pakistan. This suggests that proven effective infection control measures, though introduced, have not been successfully implemented, in general. Effective implementation of these measures can significantly reduce the risk of transmission from parenteral exposures through unsterile medical or dental equipment, and particularly IM therapeutic injections. Additional multi-disciplinary efforts involving legislators, healthcare professionals, and communities are needed to control healthcare associated HBV and HCV transmission in Pakistan and similar developing countries.

\section{Acknowledgements}

We would like to thank the study subjects for their participation and staff of the blood banks for their cooperation.

The study was supported by the Department of Community Health Sciences, The Aga Khan University, Karachi, Pakistan

\section{REFERENCES}

1. Simonsen L, Kane A, Lloyd J, Zaffran M, Kane M. Unsafe injections in the developing world and transmission of bloodborne pathogens: a review. Bull World Health Organ. 1999;77(10):789-800.

2. World Health Organization. Fact Sheet 2000. Hepatitis C. WHO/164. Geneva: WHO; 2000.

3. World Health Organization. Fact Sheet 2000. Hepatitis B. WHO/204. Geneva: WHO; 2000.

4. Centers for Disease Control(CDC). Guidelines for prevention of transmission of human immunodeficiency virus and hepatitis B virus to health-care and publicsafety workers. MMWR Morb Mortal Wkly Rep. 1989 Jun 23;38 Suppl 6:1-37. Erratum in: MMWR Morb Mortal Wkly Rep 1989 Nov 3;38(43):746.

5. Kermode M. Unsafe injections in low-income country health settings: need for injection safety promotion to prevent the spread of blood-borne viruses. Health Promot Int. 2004 Mar;19(1):95-103.

6. Allegranzi B, Pittet D. Healthcare-associated infection in developing countries: simple solutions to meet complex challenges. Infect Control Hosp Epidemiol. 2007 Dec;28(12):1323-7.

7. Luby SP, Qamruddin K, Shah AA, Omair A, Pahsa O, Khan AJ, et al. The relationship between therapeutic injections and high prevalence of hepatitis C infection in Hafizabad, Pakistan. Epidemiol Infect. 1997 Dec;119(3):349-56. 
8. Khan AJ, Luby SP, Fikree F, Karim A, Obaid S, Dellawala S, et al. Unsafe injections and the transmission of hepatitis $\mathrm{B}$ and $\mathrm{C}$ in a periurban community in Pakistan. Bull World Health Organ. 2000;78(8):956-63.

9. Pasha O, Luby SP, Khan AJ, Shah SA, McCormick JB, Fisher-Hoch SP. Household members of hepatitis C virus-infected people in Hafizabad, Pakistan: infection by injections from health care providers. Epidemiol Infect. 1999 Dec;123(3):515-8.

10. Raza MW, Kazi BM, Mustafa M, Gould FK. Developing countries have their own characteristic problems with infection control. J Hosp Infect. 2004 Aug;57(4):294-9.

11. Akhtar S, Younus M, Adil S, Jafri SH, Hassan F. Hepatitis C virus infection in asymptomatic male volunteer blood donors in Karachi, Pakistan. J Viral Hepat. 2004 Nov;11(6):527-35.

12. Chlabicz S, Grzeszczuk A, Pytel B, Prokopowicz D. Is acute hepatitis $\mathrm{B}$ still a nosocomially-acquired infection in Poland? A case-controlled study of transmission routes in a hospital sample. Scand J Infect Dis. 2002;34(11):808-10.

13. Chlabicz S, Grzeszczuk A, Prokopowicz D. Medical procedures and the risk of iatrogenic hepatitis $\mathrm{C}$ infection: case-controlled study in northeastern Poland. J Hosp Infect. 2004 Nov;58(3):204-9.

14. Janjua NZ, Hutin YJ, Akhtar S, Ahmad K. Population beliefs about the efficacy of injections in Pakistan's Sindh province. Public Health. 2006 Sep;120(9):824-33.
15. Hutin YJ, Chen RT. Injection safety: a global challenge. Bull World Health Organ. 1999;77(10):787-8.

16. Altaf A, Fatmi Z, Ajmal A, Hussain T, Qahir H, Agboatwalla M. Determinants of therapeutic injection overuse among communities in Sindh, Pakistan. J Ayub Med Coll Abbottabad. 2004 Jul-Sep;16(3):35-8.

17. Reeler AV. Anthropological perspectives on injections: a review. Bull World Health Organ. 2000;78(1):135-43.

18. Singh J, Gupta S, Khare S, Bhatia R, Jain DC, Sokhey J. A severe and explosive outbreak of hepatitis B in a rural population in Sirsa district, Haryana, India: unnecessary therapeutic injections were a major risk factor. Epidemiol Infect. 2000 Dec;125(3):693-9.

19. Butt AK, Khan AA, Khan SY, Sharea I. Dentistry as a possible route of hepatitis C transmission in Pakistan. Int Dent J. 2003 Jun;53(3):141-4.

20. Fazli Z, Asghar H, Baig NU, Fahmi A, Dil AS, Zaidi SS, et al. Prevalence of hepatitis B Virus in dental clinics in Rawalpindi/Islamabad. J Pak Med Assoc. 1998 Aug;48(8):259.

21. Schlesselman JJ, Stolley P. Case-control studies: design, conduct, analysis. New York: Oxford University Press; 1982.

Received March 25, 2008

Accepted June 24, 2008 